\title{
SPATIAL APPROACH TO DISEASES OF AFFLUENCE EPIDEMIOLOGY AND REGIONAL ECONOMIC DEVELOPMENT
}

\author{
Alicja Olejnik, Ph.D., Eng. \\ University of Lodz \\ Faculty of Economics and Sociology \\ Institute of Spatial Economics \\ Department of Spatial Econometrics \\ 37 Rewolucji 1905 r. Street, 90-214 Łódź, Poland \\ e-mail: olejnika@uni.lodz.pl \\ Agata Żółtaszek, Ph.D. \\ University of Lodz \\ Faculty of Economics and Sociology \\ Institute of Spatial Economics \\ Department of Spatial Econometrics \\ 37 Rewolucji 1905 r. Street, 90-214 Łódź, Poland \\ e-mail:zoltaszek@uni.lodz.pl
}

Received 4 January 2016, Accepted 6 October 2016

\begin{abstract}
Diseases of affluence (of the 21st c.) by definition should have higher prevalence and/or mortality rates in richer and more developed countries than in poorer, underdeveloped states (where diseases of poverty are more common). Therefore, it has been indicated that it is civilizational progress that makes us sick. On the other hand, substantial financial resources, highly qualified medical personnel, and the cutting-edge technology of richer states, should allow for effective preventions, diagnostics, and treatment of diseases of poverty and of affluence. Therefore, a dilemma arises: is progress making us sick or curing us? To evaluate the influence of country socioeconomic and technological development on population health, a spatial analysis of the epidemiology of diseases of affluence and distribution of economic resources for European NUTS 2 has been performed. The main aim of this paper is to assess, how regional diversity in the prevalence of diseases of affluence is related to the regional development of regions.
\end{abstract}

Keywords: diseases of affluence, health, socioeconomic development, spatial autocorrelation, spatial econometric model 


\section{Introduction}

For centuries, fatal and communicable diseases like the "Black death" created havoc across Europe. (Haensch et al., 2010; Scott, Duncan, 2007) Today, we are incomparably much more knowledgeable in many aspects of the microbiology and epidemiology of transmittable diseases. However, the knowledge we have is not enough in eradicating all the possible "plagues". The Asian SARS epidemic in 2003 and lasting since 2013 the Ebola virus epidemic in West Africa is proof of that (Scott, Duncan, 2007; Cook, Halsall 2012). Nevertheless, the most communicable diseases are typical epidemic problems in poorer regions, so they are rather perceived as diseases of poverty than affluence.

Diseases of affluence, also known as diseases of the 21st c., Western diseases or in Polish civilizational diseases, have been defined as diseases with higher prevalence and/or mortality rates in richer and more developed countries than in poorer, underdeveloped states, where on the contrary diseases of poverty are more common. Therefore, it has been indicated that it is civilizational progress that makes us sick. The affluence hypothesis has been stated on numerous occasions suggesting the undesirable medical effect of progress: over time, across regions, or income groups, both in a macro and micro scale. It can be summarized that: the more affluent (wealthy, developed etc.) the object (country, region, social group, household, person etc.), the more intense the prevalence (frequency of cases, severity of symptoms, mortality rate etc.) of the disease.

Diseases of affluence have become one of the leading problems in epidemic analyses. Many WHO reports indicate the growing importance of preventing epidemics, proper diagnostics, and treatment. The main concerns are the growing medical and social costs of afflictions that plague highly developed societies (WHO Global health risks; WHO Global Report, WHO Global status; WHO Health in 2015; WHO Noncommunicable; WHO World health statistics 2014; Chan, Bloomberg, 2016). The economic factor is also crucial. Health economics states that the relationship between economy and health, both in a micro and macro scale, are strong and bidirectional. Too low expenditures on health care cause a deterioration of public health, which in consequence results in the decrease of productivity, greater absenteeism, and loss-of-life costs (Frenk, 2004; Żółtaszek, Budny, 2016). On the other hand, socioeconomic and technological development brings drastic changes in lifestyles (e.g. less physical activity, unbalanced diet), environmental degradation and chemical enhancements in food and cosmetics, which may cause or stimulate additional medical issues (Aue, 2009; Bender, 2015; Campbell, Campbell, 2013; Cook, Halsall, 2012; Ferrante, 2014; Roik 2008). 
Nowadays, cardiovascular problems (one of the main diseases of affluence) are a major cause of death in developed countries leading to over $30 \%$ of all deaths (for instance in 2013: $37 \%$ for the EU 28, 40\% in Germany, 46\% in Poland, up to 65\% in Bulgaria - see Eurostat database). (WHO Cardiovascular diseases, WHOGlobal Health Observatory) There is no standardized list of disease of affluence. However, it is often indicated that they include: cardiovascular diseases, respiratory system diseases, cancer, obesity, diabetes, allergies, mental disorders, and HIV (which has some characteristics of both diseases of poverty and affluence) (Ferrante, 2014; Kotarski, 2013; Roik, 2008). The growing global problem with these noncommunicable diseases is a fact. However, there is no irrefutable evidence that the prevalence of these afflictions is stimulated by economic and social development. It is generally believed that regions with higher economic indicators are more at risk, than poorer ones. They are considered to be the cost and by-product of social, cultural, technological, and economic progress in highly developed societies (Kotarski, 2013; Link, 2007; Aue, 2009). Most of these are chronic diseases, which mean that their duration exceeds 3 to 6 months (depending on the source of the definition) or even extends to whole life. Very often, the period of development of the diseases is also typically large (WHO Non communicable; Ferrante, 2014). However, no clear spatial patterns have been confirmed. Proving or disproving some of the common notions could be very beneficial for developing and assessing regional, international, and global policies on the diseases of the 21 stI $c$.

On the other hand, substantial financial resources, highly qualified medical personnel, and the cutting-edge technology of richer states, should favour effective prevention, diagnostics, and treatment of both, diseases of poverty and diseases of affluence. Therefore, a question arises: is progress making us sick or curing us? To evaluate the influence of a country's socioeconomic and technological development on population health, a spatial analysis of epidemiology of diseases of affluence and distribution of economic resources has been performed. The main aim of this paper is to assess, how regional diversity in the prevalence of diseases of affluence is related to the level of development of regions.

The prevalence of the main diseases of affluence differs strongly from disorder to disorder and changes over time and space (WHO Global Health Observatory; WHO Global health risks; WHO Global Report; WHO Global status; WHO Health in 2015; WHO Non communicable; WHO World health statistics, 2014; Żółtaszek, Budny, 2016). However, in each case the hypothesis of affluence influencing prevalence has been rising in some way. Often the association between wealth and illnesses is suggested by medical doctors based on their knowledge and experience and not objective spatiotemporal data analysis. The statistical approach could finally 
prove or disprove the existence of diseases of affluence. Yet lacking comparable data makes it very difficult or even impossible. There are limited data on the prevalence of each illness with: (1) a time series long enough to verify the hypothesis and (2) spatial data (not only by country but by smaller regions) for worldwide comparisons. Usually the available information on diseases of affluence states the mortality rates (based on cause of death) which does not reflect the prevalence. Firstly, people suffer from a certain disease do not necessarily die because of it. They can be killed in accidents, by other illnesses, or murdered. Especially in high-income countries with good healthcare systems and modern medicine, most diseases of affluence can be cured or managed elongating the expected lifespan, which increases the probability of different causes of death. Secondly, if the affluence hypothesis is true and wealth (for example GDP per capita, income per household member) causes a higher frequency of becoming ill or more severe symptoms there may be another effect in an opposite direction: (1) the richer country, region, person, or household, the higher expenditures on health (public, private, and total); (2) the higher the medical expenses, the better the health care in aspect of accessibility, diagnostics, technology, human resources; (3) the better health care, the lower mortality of any medical cause including diseases of affluence.

Therefore even if affluence may cause higher prevalence it may as well lower the mortality of diseases of the $21 \mathrm{st} \mathrm{c}$. Thus, mortality statistics may be underestimated as a measurement of prevalence due to both factors. Moreover the "double-aged sword" of affluence makes it difficult to "guess" which effect is stronger and is the tendency constant over time, space, and disease. Analysing spatial patterns of mortality due to each illness and their dependence with economic progress may not give any final proof of the existence of diseases of affluence and solve all of the connected problems. It will, however, deliver crucial insight into the mystery of the diseases of affluence.

The paper is structured as follows. Section 2 introduces some of the methodology used in the study and the results of our empirical analysis. Finally, Section 3 provides a summary and some concluding remarks.

\section{Methodology and Empirical Analysis}

To assess the regional influence of economic progress on the state of population health some spatial analysis tools were employed. The research was carried out on NUTS $2^{1}$ European

\footnotetext{
1 NUTS 2 - Nomenclature of territorial units for statistics is a hierarchical system for dividing up the economic territory of the EU for the purpose of the collection, development and harmonisation of European regional statistics,
} 
Union regional level based countries on the Eurostat dataset (Eurostat database). The data used made it possible to evaluate the influence of economic factors as well as recognize some spatial patterns of prevalence and mortality rates for the chosen diseases of affluence.

In the analysis below we have used some Spatial Statistics technics. Namely, local and global Moran's $I$ statistics both uni- and bivariate ones.

The Moran's I statistic (Moran, 1947; Cliff, Ord, 1981) is one of the most popular tests for spatial association. The local Moran's $I_{i}$ shows whether the $i$-th location is surrounded by locations with similar (positive spatial autocorrelation) or significantly different values (negative spatial autocorrelation). The local Moran's $I_{i}$ statistic is a base for Local Indicators of Spatial Association - LISA. The local Moran's $I$ statistic takes the following form:

$$
I_{i}=\frac{\left(x_{i}-\overline{\boldsymbol{x}}\right)}{\frac{1}{N} \sum_{j=1}^{N}\left(x_{j}-\overline{\boldsymbol{x}}\right)^{2}} \sum_{j=1}^{N} w_{i j}\left(x_{j}-\overline{\boldsymbol{x}}\right)
$$

The global Moran's I measures general regional similarity for all regions as a mean of local Moran's $I_{i}$ statistics. The global Moran's $I$ statistic can be presented as follows:

$$
I=\frac{\sum_{i=1}^{N} \sum_{j=1}^{N} w_{i j}\left(x_{i}-\overline{\boldsymbol{x}}\right)\left(x_{j}-\overline{\boldsymbol{x}}\right)}{\frac{1}{N} \sum_{i=1}^{N}\left(x_{i}-\overline{\boldsymbol{x}}\right)^{2}}
$$

where $\overline{\boldsymbol{x}}$ means mean of a given process and $w_{i j}$ elements of the $\mathbf{W}$ matrix. We assume a positive spatial autocorrelation if: $I>-\frac{1}{N-1}$ and a negative spatial autocorrelation otherwise.

Bivariate Local Moran's I Measures spatial correlation between x and other variable (y) in nearby areas:

$$
I_{i}=\frac{\left(x_{i}-\overline{\boldsymbol{x}}\right)}{\frac{1}{N} \sum_{j=1}^{N}\left(x_{j}-\overline{\boldsymbol{x}}\right)^{2}} \sum_{j=1}^{N} w_{i j}\left(y_{j}-\bar{y}\right)
$$

In the analysis below we considered the gross domestic product (GDP) at current market prices by NUTS 2 EU regions in the Purchasing Power Standard per inhabitant in the year 2011 and six crude death rate by the NUTS 2 EU region of residence caused by: diabetes mellitus, HIV, neoplasms, diseases of the circulatory system, mental and behavioural disorders, and 
diseases of the respiratory system in the year 2011. ${ }^{2}$ All spatial analysis are based on the queen contiguity spatial weight matrix, 1st order (Anselin, 1988).

For diabetes as a cause of death we can observe a high concentration in Italy, Southern Germany, and the Western Iberian Peninsula. High and significant Moran's $I=0.57$ statistic indicates that there is high positive spatial autocorrelation and therefore the high number of deaths caused by diabetes mellitus in a particular region (especially for Italy, Southern Germany, and the Western Iberian Peninsula) increase the probability of high number of deaths in neighbouring regions. Moreover, we can distinguish three clusters of high numbers of deaths caused by diabetes mellitus and some clusters of a low-low relation including Finland and the UK. Bivariate Moran's I analysis shows that the eastern part of the European Union constitutes a cluster in which regions with low numbers of deaths caused by diabetes mellitus are surrounded by regions with a low level of Gross domestic product. On the other hand in Southern Germany with regions with high death rates correlate with high GDP. ${ }^{3}$ Global bivariate Moran's $I=0.1$ therfore the global effect is not strong however significant (p-value $=0.003$ ). (see Figures 1, 2, 3) This means that in these regions diabetes is a disease of affluence.

The second analysed cause of death was Human immunodeficiency virus - HIV (crude death rate in 2011 by NUTS 2 EU region of residence). HIV is mostly a STD (sex transmitted disease) and therefore its prevalence depends on the knowledge of it and lifestyle. It cannot be cured but can be controlled. We can observe high concentrations of the phenomenon in Southern Europe which indicates that people do not kwon how to prevent and diagnose the infection (for example due to high migration from less developed regions or lacking sex education) and display hazardous behaviours (like sex with multiple partners, without protection etc.). Moran's $I=0.68$ statistic indicates that there is high positive spatial autocorrelation and therefore the high number of deaths caused by HIV in a given region increases the probability of a high number of deaths in neighbouring regions. Moreover, we can distinguish one cluster of high number of deaths caused by HIV - Italy and neighbouring regions. Similarly to diabetes, for HIV bivariate Moran's I analysis shows that (1) the eastern part of the European Union constitutes a cluster in which regions with low numbers of deaths caused by HIV are surrounded by regions with a low level of GDP and (2) in some part of Germany regions with high death rates are connected with regions with high GDP. Global bivariate Moran's is again $I=0.1$ therefore the global effect is not strong though significant. (see Figures 1, 2, 3) Again, this proves that in some EU regions HIV is a disease of affluence.

\footnotetext{
2 All data source is: Eurostat Regions Data (http://ec.europa.eu/eurostat/web/regions/data).

3 GDP at current market prices by NUTS 2 regions in PPS per inhabitant, ESA 2010.
} 


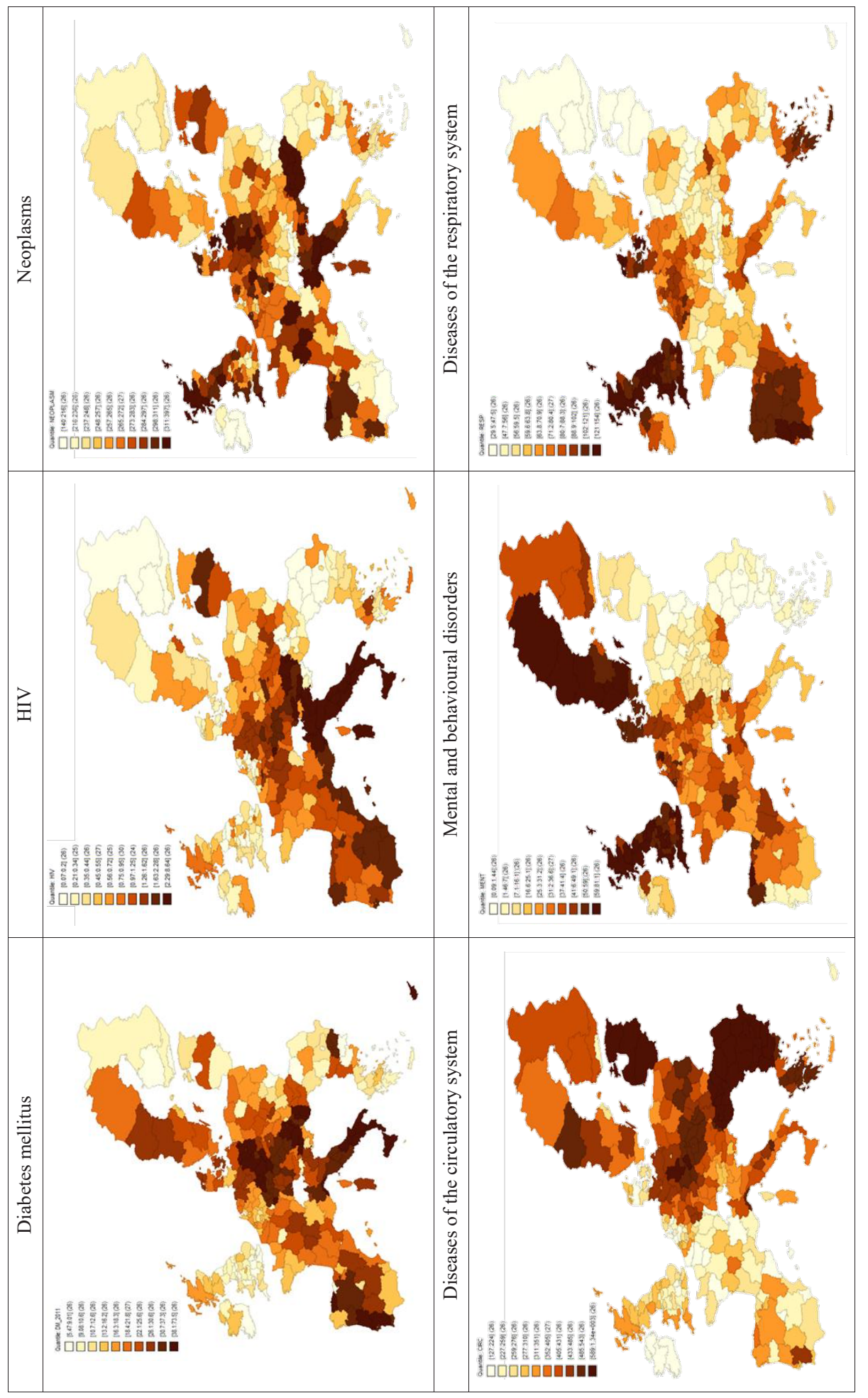

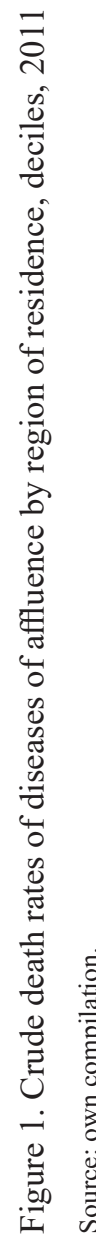


Another cause of death was neoplasms or cancer. Medically it is not clear which external factors stimulate the prevalence, which makes it difficult to analyse. Generally, some groups of concentration of the phenomenon can be observed all over Europe, especially in Western and Southern regions. Moran's $I=0.38$ statistic indicates that there is not a very strong however significant positive spatial autocorrelation. Moreover, we can distinguish some clusters of high numbers of deaths caused by neoplasms (high-high) - parts of the UK, Northern Germany, Northern Italy, the Northern Balkans, low number of deaths (low-low) - Ireland, Eastern Spain, the Central Balkans, Southern Poland, regions with high numbers of deaths surrounded by low numbers of deaths (high-low) - the Southern Balkans, Eastern England, and finally a low number of deaths surrounded by a high number of deaths (low-high) - Southern France. Bivariate Moran's I analysis shows that the eastern part of the EU constitutes a cluster of low numbers of deaths caused by Neoplasms and some high numbers of deaths surrounded by low numbers with some high-low amongst them. There are also some clusters of high-high relations in the central part of the EU in Germany intertwined with low-high regions. Global bivariate Moran's $I=0.06$ suggest that the global effect is weak but still significant. (see Figures 1, 2, 3) These still can be treated as some kind of indication of affluence - prevalence correlation.

In the next step of analysis, diseases of the circulatory system were considered. They are strongly related to risk factors like obesity, age, alcohol consumption etc. We can observe a concentration of the phenomenon in central and Eastern Europe (especially the Balkans, and the Baltic States). Moran's $I=0.83$ statistic indicates that there is a high positive spatial autocorrelation of death rate caused by diseases of the circulatory system. Moreover, two clear clusters can be distinguished: high number of deaths caused by diseases of the circulatory system in the Southern-East EU and a low prevalence in the Western regions of the EU. It can be noticed that there are no high-low and low-high clusters. Bivariate Moran's I analysis shows that the eastern part of the EU constitutes a cluster of high numbers of deaths caused by diseases of the circulatory system surrounded by regions with low levels of GDP. In Germany, except for some northern regions with a high-high relation most of the regions have low numbers of deaths surrounded by regions with high GDP. Global bivariate Moran's $I=-0.37$ indicates that the global effect is small but significant (see Figures 1, 2, 3). This actuality rather disproves the affluence hypothesis at least based on the mortality since prevalence data are not available.

Mental and behavioural disorders can be based on genetical and external factors. We can observe a concentration of death rates in regions of the Northern EU (Scandinavia and the UK). Moran's $I=0.78$ statistic indicates that there is high positive spatial autocorrelation of death rate caused by mental and behavioural disorders. Moreover, two clear clusters can be distinguished: 


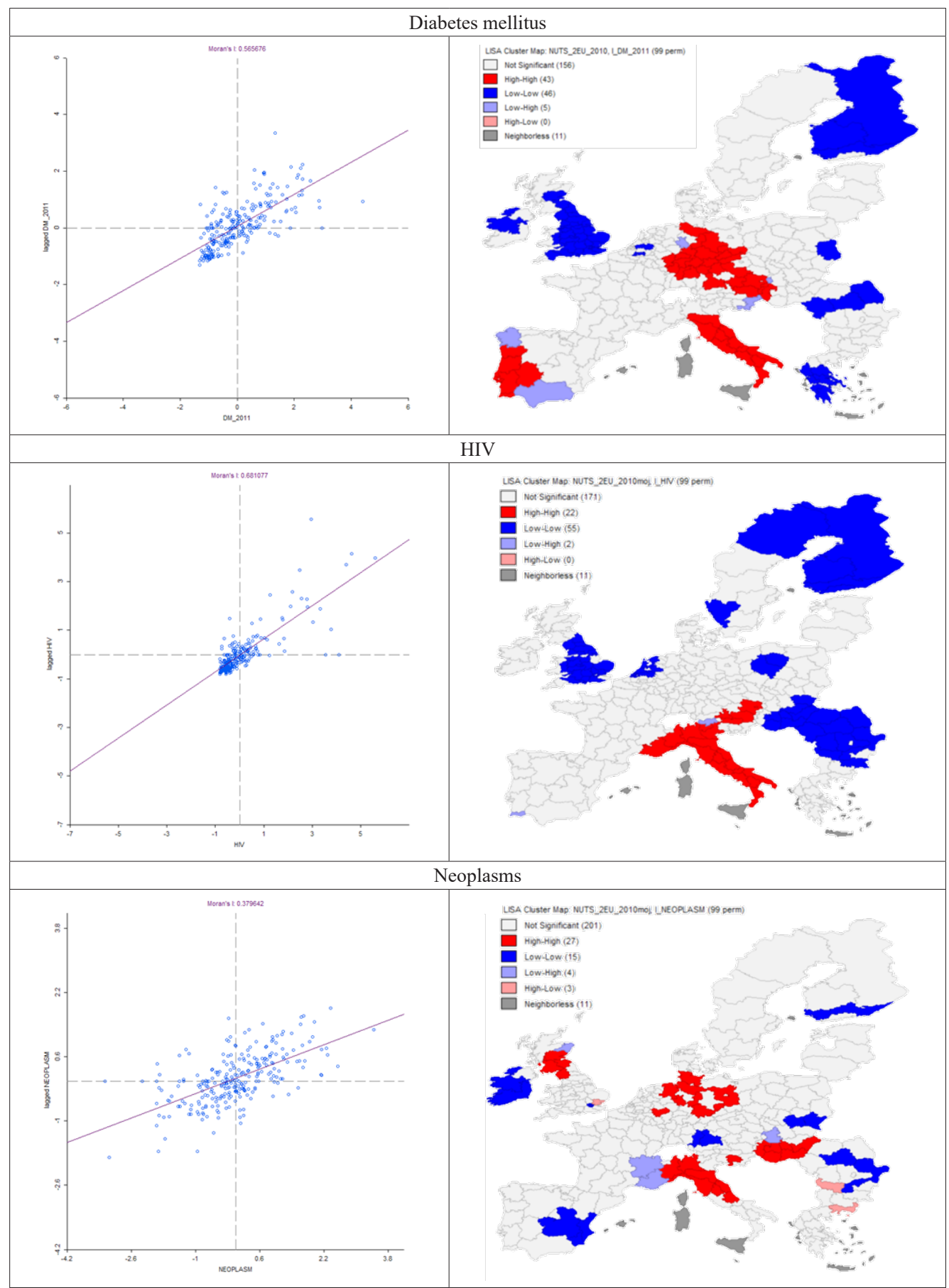

Figure 2a. Moran's Scatterplots and LISA for diseases of affluence (part I)

Source: own compilation. 


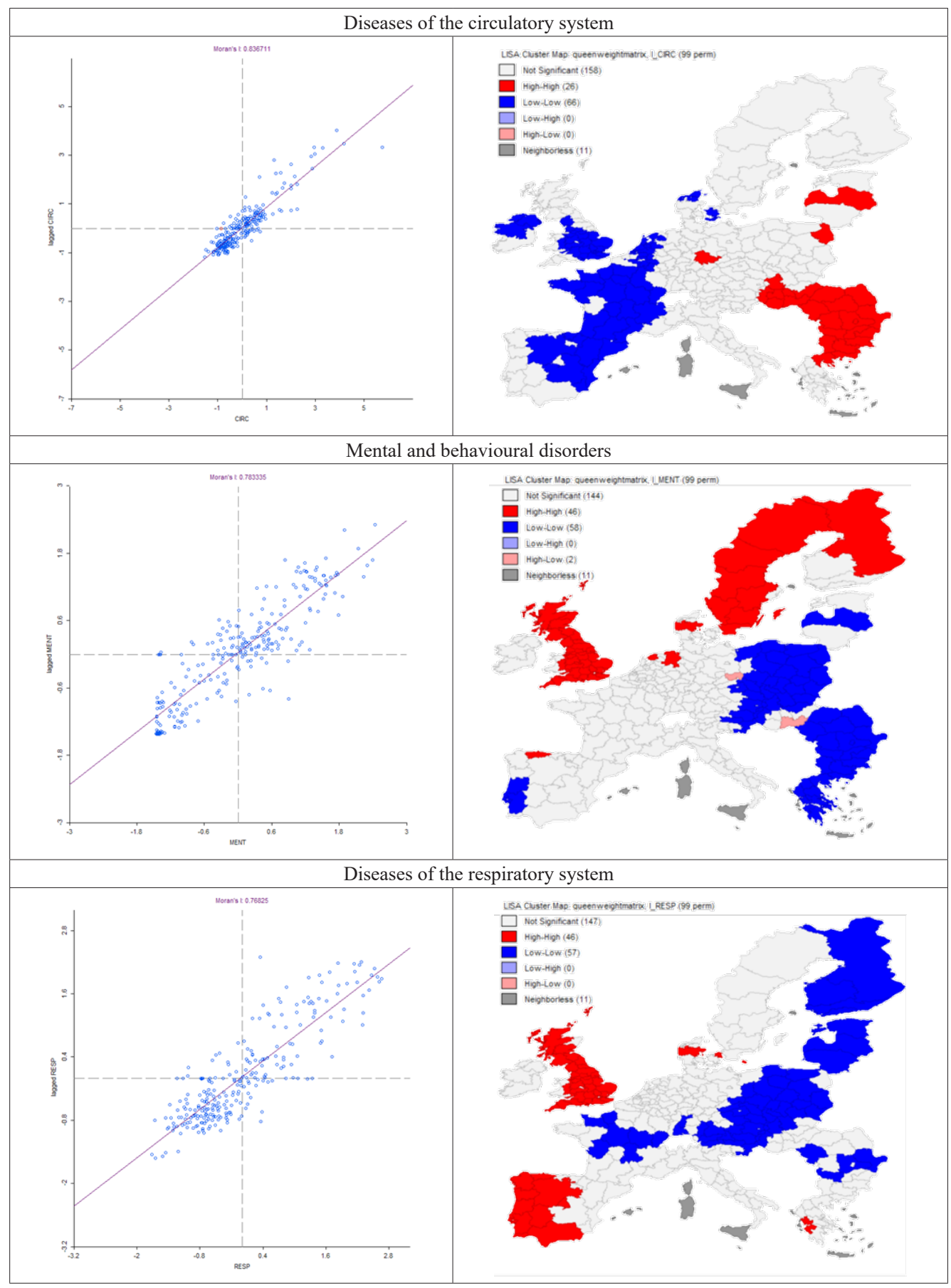

Figure 2b. Moran's Scatterplots and LISA for diseases of affluence (part II)

Source: own compilation. 


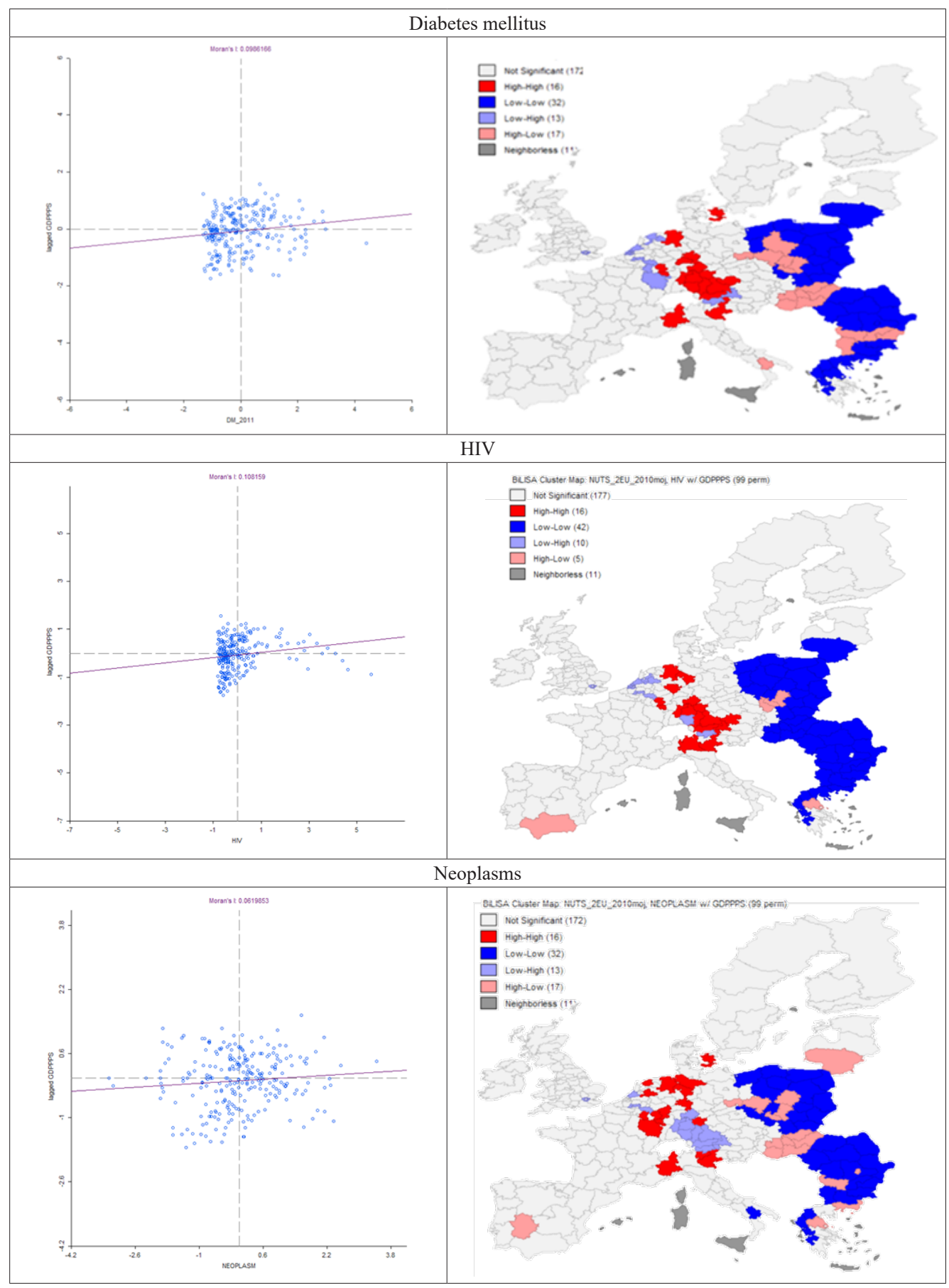

Figure 3a. Global and local bivariate Moran's I for diseases of affluence and GDP (part one) Source: own compilation. 


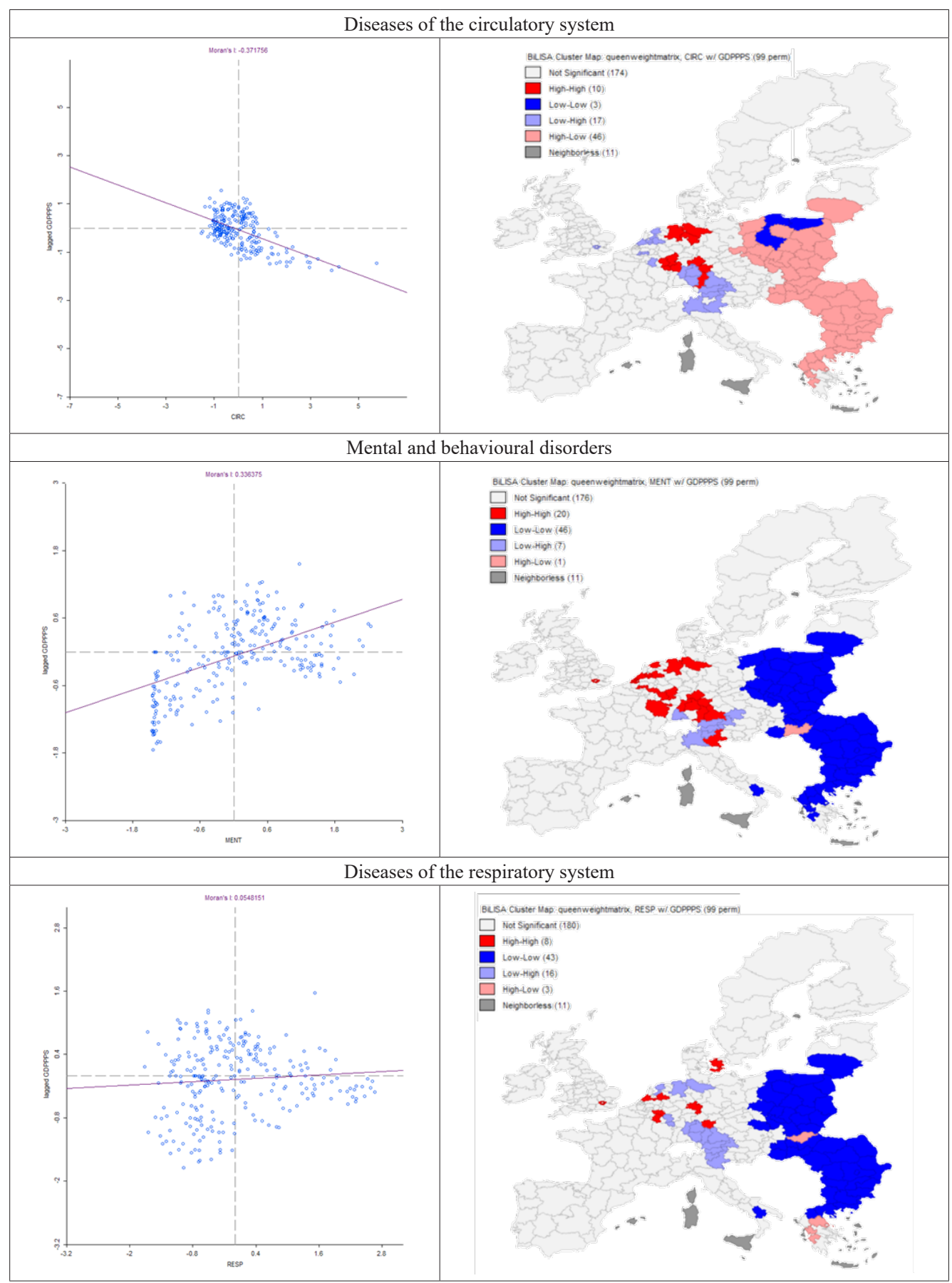

Figure 3b. Global and local bivariate Moran's I for diseases of affluence and GDP (part II) Source: own compilation. 
high number of deaths caused by mental and behavioural disorders in the Northern EU and a low number of deaths in Eastern regions of the EU. Bivariate Moran's I analysis shows that the eastern part of the EU constitutes a cluster of a low number of deaths caused by mental and behavioural disorders surrounded by a low level of GDP. There are also some clusters of highhigh relations in the central part of the EU (in Germany); where high a level of deaths caused by mental and behavioural disorders is surrounded by a high level of GDP. Global bivariate Moran's $I=0.34$ suggest that the global effect is quite strong and significant. (see Figures 1 , $2,3)$ This outcome supports the hypothesis of affluence especially that regions with low GDP correlate with low death rates.

Finally the last analysed cause of death were diseases of the respiratory system, which are assumed to be caused mostly by lifestyle factors (like smoking, obesity). Diseases of the respiratory system are highly concentrated in the UK, Denmark, the Iberian Peninsula, and the Southern Balkans. Moran's $I=0.77$ statistic indicates that there is a high positive spatial autocorrelation of death rate caused by diseases of the respiratory system. There are some high-high and low-low clusters and no high-low and low-high clusters. High death rate regions create large clusters in the whole of the UK and most of the Iberian Peninsula. Regions with a low-low relation are grouped diagonally across Europe from Scandinavia, the Baltic States, Central Europe, and some parts of France and the Balkans. Bivariate Moran's I analysis shows that the eastern part of the EU constitutes a cluster of regions with a low number of deaths caused by diseases of the respiratory system surrounded by the low level of GDP. There are also few and small clusters of high-high and low-high relations in the central part of the EU. The Global bivariate Moran's $I=0.54$ indicates that the global spatial effect is strong and significant (see Figures 1, 2, 3). This again partly confirms the affluence character of diseases of the respiratory system, but rather with low prevalence in low-income regions.

A spatial correlation analysis of mortality rates indicates that: (1) Germany has a cluster of high mortality rate regions with diabetes and cancer, (2) Italy has a cluster of high mortality rate regions for diabetes, HIV, and cancer, (3) the Iberian Peninsula has some clusters of high mortality rate regions for diabetes and diseases of the respiratory system but also a cluster of low mortality rates for diseases of the circulatory system, mental and behavioural disorders, and cancer, (4) the UK has a cluster of high mortality rate regions for cancer, mental and behavioural disorders, and diseases of the respiratory system but also a cluster of low mortality rates for diabetes, HIV, and diseases of the circulatory system, (5) Scandinavia has a cluster of high mortality rate regions for mental and behavioural disorders but also a cluster of low mortality rates for diabetes, HIV, and diseases of the respiratory system, (6) the Balkans have a cluster of high mortality rate regions 
for diseases of the circulatory system but also a cluster of low mortality rates for diabetes, HIV, cancer, mental and behavioural disorders, and diseases of the respiratory system, (7) Central Europe, with Poland, creates a cluster of low mortality rate regions for mental and behavioural disorders, and diseases of the respiratory system, (8) France has a cluster of low mortality rates for diseases of the circulatory system and diseases of the respiratory system.

In the case of high mortality in Germany, the UK, Scandinavia, Italy, the Iberian Peninsula as wealthy regions and on the other hand low mortality in the Balkans, Central Europe some diseases seem to prove the affluence hypothesis. The low mortality in France and Scandinavia does not disprove the hypothesis but simply suggests that the health care effect is stronger than any possible increase in the prevalence of illnesses.

Analysing the bivariate spatial correlation with GDP we can observe that: (1) Germany has some small clusters of regions with high mortality surrounded by regions with high GDP for every disease, (2) Central and Eastern Europe (the Balkans, Poland, Slovakia, Czech Republic, the Baltic States) create large clusters of regions with low mortality rates with high-GDP neighbouring regions for every illness except diseases of the circulatory system where almost the same cluster combines regions where high mortality borders with low GDP.

Thus, the affluence hypothesis may be true but in reverse: low-GDP regions have low mortality or prevalence or minor symptoms as for example Central and Eastern Europe. The only exception is a group of cardiovascular diseases which is a major problem in these poorer regions (probably due to traditional alcohol abuse and therefore unconnected to the GDP level).

\section{Conclusions}

Diseases of affluence are perceived as one the major risks of the $21 \mathrm{st}$ c. They are the cost of socioeconomic development and induced lifestyle changes. However, from the quantitative point of view, proving that economic progress is responsible for increasing the incidence rates is very difficult to establish. Especially that medical foundations do not clearly define the sources of these illnesses, leaving us with no obvious clue. Therefore, it would be valuable to conduct an exhaustive quantitative spatial analysis on the problem. Unfortunately, epidemiological statistics over time and space are scarce, which effectively hinders the desired research. The approach assumed in this paper is to analyse mortality rates instead of prevalence per se. This might be not a perfect proxy, however as the only possibility, we believe it can still lead to valuable and reliable conclusions.

In this paper an attempt at researching spatial patterns in Western diseases for European NUTS 2 has been made. Our results strongly suggest that some of the investigated diseases 
(like mental disorders, diseases of the respiratory system, neoplasms) have an established spatial pattern, and they are often correlated with the level of economic development. Although, some regions are more prone to the prevalence - development dependence (i.e. Central and Eastern Europe) than others. Our results may not be ultimate proof of the existence of diseases of affluence, but they do strongly suggest that some of the investigated diseases have an established spatial pattern, and they are often correlated with the level of economic development.

We believe that the methodology used is appropriate due to the spatial nature of the addressed problems. The link between economic development and the diseases of affluence at the regional level has been proven. The aim of the research has been fulfilled by the analysed data and the affluence hypothesis, although not omnipresent and omnipotent, have been proven to be plausible. Nevertheless, additional work needs to be done. The spatial Durbin model with spatially lagged GDP seems to be a good direction in any further analysis of this problem. Therefore, we hope that this paper will increase the attention given to this topic by applying spatial econometric tools in the epidemiology of diseases of affluence.

\section{References}

Anselin, L. (1988). SpatialEconometrics: Methods and Models. Dordrecht: Kluwer Academic Publications.

Aue, W. (2009). Człowiek w środowisku: podręcznik. Cz. 1, WSiP.

Bender, D.A. (2015). Introduction to Nutrition and Metabolism. Fifth Edition. CRC Press.

Campbell, T.C., Campbell, T.M. (2013).The China Study: The Most Comprehensive Study of Nutrition Ever Conducted and the Startling Implications for Diet, Weight Loss and Long-Term Health. Ben Bella Books, Inc.

Chan, M., Bloomberg, M.R. (2016). Political will needed to win fight against noncommunicable diseases. WHO commentary. Available at: http://www.who.int/mediacentre/commentaries/political-noncommunicable-diseases/en (11.10.2016).

Cliff, A., Ord, J.K. (1981). Spatial Processes: Models and Applications. Pion, London.

Cook, I.G., Halsall, J. (2012). Aging in Comparative Perspective: Processes and Policies. Springer Science \& Business Media.

Eurostat Database, http://ec.europa.eu/eurostat/data/database.

Eurostat NUTS overview, http://ec.europa.eu/eurostat/web/nuts/overview.

Eurostat Regions Data, http://ec.europa.eu/eurostat/web/regions/data. 
Ferrante, J. (2014). Sociology: A Global Perspective. Cengage Learning.

Frenk, J. (2004). Health and the economy: A vital relationship. OECD Observer. Available at: http://oecdobserver.org/news/archivestory.php/aid/1241/Health_and_the_economy:_A_ vital_relationship_html (11.10.2016).

Haensch, S., Bianucci, R., Signoli, M., Rajerison, M., Schultz, M., Kacki, S., ..., Bramanti, B. (2010). Distinct Clones of Yersinia pestis Caused the Black Death. PLOS Pathogens, 6 (10): e1001134. DOI: 10.1371/journal.ppat.1001134. Available at: https://www.ncbi. nlm.nih.gov/pmc/articles/PMC2951374 (26.06.2015).

Kotarski, H. (2013). Kapitał ludzki i kapitał społeczny a rozwój województwa podkarpackiego. Rzeszów: Wydawnictwo Uniwersytetu Rzeszowskiego.

Link, K. (2007).Understanding New, Resurgent, and Resistant Diseases: How Man and Globalization Create and Spread Illness. Greenwood Publishing Group.

Moran, P. (1950). Notes on Continuous Stochastic Phenomena. Biometrika, 37, 17-23.

Roik, J. (2008). Choroby cywilizacyjne, Partner Złote Myśli.

Scott, S., Duncan, C. (2007).Return of the Black Death: The World's Greatest Serial Killer. John Wiley \& Sons.

WHO Cardiovascular diseases (CVDs) Fact sheet (2016). Available at: http://www.who.int/mediacentre/factsheets/fs317/en (11.10.2016).

WHO Global Health Observatory. Available at: http://www.who.int/gho/map_gallery/en (29.06.2015).

WHO Global health risks: Mortality and burden of disease attributable to selected major risks (2009). Available at: http://www.who.int/healthinfo/global_burden_disease/global_ health_risks/en (11.10.2016).

WHO Global Report on Urban Health (2016). Available at: http://www.who.int/kobe_centre/ measuring/urban-global-report/en (11.10.2016).

WHO Global status report on alcohol and health 2014. Available at: http://www.who.int/substance_abuse/publications/global_alcohol_report/en (11.10.2016).

WHO Health in 2015: from MDGs to SDGs. Available at: http://www.who.int/gho/publicationsmdgs-sdgs/en (11.10.2016).

WHO Noncommunicable diseases Fact sheet. Available at: http://www.who.int/mediacentre/ factsheets/fs355/en (29.06.2015).

WHO World health statistics 2014. Available at: http://www.who.int/gho/publications/world health_statistics/2014/en (11.10.2016).

Żółtaszek, A., Budny, D. (2016). Czy postęp cywilizacyjny jest dla nas zdrowy? Analiza wydatków na ochronę zdrowia i aspektów epidemiologicznych wybranych chorób cywilizacyjnych. In: B. Dańska-Borsiak, I. Laskowska (eds.), Regionalne analizy ekonomiczne: Ekonomia (pp. 83-98). Łódź: Wydawnictwo Uniwersytetu Łódzkiego. 